\title{
Summary of Mayor Krystian Kinastowski's presentation at the Calisia World Conference on Family Health
}

\author{
Krystian Kinastowski \\ President of the City of Kalisz
}

ADDRESS FOR CORRESPONDENCE: Krystian Kinastowski, D.H.Sc., President of the City of Kalisz

Supplementary materials (slides) are available in Webappendix 15 at the journal's website: https://www.termedia.pl/Journal/Journal_of_ Health_Inequalities-100.

Kalisz, the oldest city in Poland, is famous for its Calisia pianos, its aerospace industry, and its centres of research excellence, such as the Didactic Centre of Gear Wheels at the President Stanisław Wojciechowski State University of Applied Sciences. The city boasts world-class cultural events - the Kalisz Theatre Meetings, the International Jazz Piano Festival, and concerts of the Grammy Award-winning Kalisz Philharmonic. With a population of over 100,000 , it is the leading urban centre of the Kalisz-Ostrów agglomeration.

Historically, the development of healthcare has been linked with the evolution of cities. In Poland, medical services were initially organised in monasteries. The first hospital in Kalisz, the Holy Spirit Hospital, was established in the $13^{\text {th }}$ century. Another one, the Holy Trinity Hospital, was built 200 years later and operated for almost five centuries. Contemporary Kalisz can boast several hospitals in its vicinity - the Ludwik Perzyna Regional Polyclinical Hospital, Radiotherapy Unit III (Kalisz Branch of the Greater Poland Cancer Centre), and the Regional Specialist Healthcare Centre of Pulmonary Diseases and Tuberculosis in Wolica.

Numerous activities of the local government of Kalisz are related to health care and are included in the Municipal Programme for Health Protection and Promotion in Kalisz for 2017-2020. These include four preventive health programmes:

1. Breast cancer early detection programme, including mammography for female Kalisz residents aged 40-49 years. Educational materials are also distributed, and consultations on further treatment are provided if lesions are detected.

2. Influenza vaccination programme for Kalisz residents aged over 60 years. Educational activities are also carried out. The objective of 634 vaccinations was met last year.
Faced with huge interest, the programme will be expanded in order to achieve the highest possible immunity levels.

3. Human papilloma virus (HPV) prevention programme, which includes the examination and vaccination of girls born in 2006. Already 58 girls have been vaccinated. The programme will be expanded to include boys, who at present are only offered educational support.

4. Sports medicine for children and adolescents who actively engage in sports. The programme comprises exercise stress tests, electrocardiogram (ECG) and electroencephalogram (EEG) tests, as well as urine and blood tests.

Events, known as White Saturdays, are also organised in Kalisz. Each of them involves thousands of free examinations and consultations - over 26,000 were provided for Kalisz residents between 2010 and 2014. A further 19,000 were carried out during the next term of office, when the fairs were called Healthy Kalisz. After returning to the old name this year over a thousand free examinations and consultations have been carried out on five White Saturdays, and seven more events are planned. The action will be continued in future years.

Kalisz residents are encouraged to take care of their physical health. A programme of sports activities, Community Coach, is offered at several sports fields. Gymnastics for seniors is organised for the elderly. There are also many preventive educational programmes and outdoor gyms, which have been installed in almost every district in Kalisz. All these initiatives have one purpose - better health!

Key words: Calisia World Conference, family health, preventive health programmes.

\section{DISCLOSURE}

The author reports no conflict of interest. 